Beemsterboer, P.M.M., Koning, H.J. de, Looman, C.W.N., Borsboom, G.J.J.M., Bartelds, A.I.M., Maas, P.J. van der. Mammography requests in general practice during the introduction of nationwide breast cancer screening, 1988-1995. European Journal of Cancer: 1999, 35(3), 450454

\begin{tabular}{|l|l|}
\hline $\begin{array}{l}\text { Postprint } \\
\text { Version }\end{array}$ & 1.0 \\
\hline Journal website & $\underline{\text { http://www.ejcancer.info/article/S0959-8049(98)00377-3/abstract }}$ \\
\hline Pubmed link & $\underline{\text { http://www.ncbi.nlm.nih.gov/pubmed/10448298 }}$ \\
\hline DOI & $10.1016 /$ S0959-8049(98)00377-3 \\
\hline
\end{tabular}

This is a NIVEL certified Post Print, more info at http://www.nivel.eu

\title{
Mammography Requests in General Practice During the Introduction of Nationwide Breast Cancer Screening, 1988-1995
}

\author{
P.M.M. BEEMSTERBOER, ${ }^{1}$ H.J. DE KONING, ${ }^{1}$ C.W.N. LOOMAN, ${ }^{1}$ G.J.J.M. BORSBOOM, ${ }^{1}$ \\ A.I.M. BARTELDS ${ }^{2}$ AND P.J. VAN DER MAAS ${ }^{1}$ \\ ${ }^{1}$ Department of Public Health, Erasmus University Rotterdam, PO Box 1738, 3000 DR \\ Rotterdam; and \\ ${ }^{2}$ The Netherlands Institute of Primary Health Care, Utrecht, The Netherlands
}

Introducing an organised breast cancer screening programme for certain age groups in a population might induce opportunistic screening in adjacent (noninvited) age groups and influence health behaviour in the target population. We analysed the effect of the start of the Dutch national screening programme on the number of mammographies requested by $43-45$ general practices for the age groups 30-39, 40-49, 50-69 and 70+ years, using logistic regression analysis. In all age groups an immediate increase was observed in the number of mammography requests after the start of the screening, which was largest and statistically significant in the target population of the screening programme (age 50-69 years). More than 2 years after the start of screening, the number of mammography requests in all age groups had decreased to the level before the start and in the age group 50-69 years the number of mammographies was significantly lower than before the screening started.

The unexpected increase in mammographies after the start of the breast cancer screening programme might be related to registry problems or to the process of building up the screening programme. Eventually there was a decrease in the number of mammographies in the target population, probably an effect of the introduction of the national screening programme. Opportunistic screening was not clearly

\section{INTRODUCTION}

The Dutch national breast cancer screening programme started in 1989. Since then, women aged from 50 to 69 years have been actively invited for biennial screening with mammography. The participation rate is $80 \%$ [1, 2]. Before screening was introduced, a costeffectiveness analysis estimated a $16 \%$ reduction of breast cancer mortality in the total female population [3]. Early effectiveness indicators of the screening programme are 
Beemsterboer, P.M.M., Koning, H.J. de, Looman, C.W.N., Borsboom, G.J.J.M., Bartelds, A.I.M., Maas, P.J. van der. Mammography requests in general practice during the introduction of nationwide breast cancer screening, 1988-1995. European Journal of Cancer: 1999, 35(3), 450454

encouraging [2]. The detection rate at first screening was approximately 6.4 per 1000 screens, in accordance with expectations. The stage distribution of the screen-detected cancers was much more favourable than for breast cancer clinically diagnosed before the start of the screening programme $[1,2]$.

The expected changes in diagnostic procedures have also been published [4]. One hypothesis was that the number of mammographies undertaken outside the screening programme in the target population would decrease, because of the introduction of screening. However, it was considered that the introduction of screening might induce more mammographies in adjacent (non-invited) age groups. Opportunistic screening in the target population could negatively influence the effectiveness of screening and costs of health care. Induced opportunistic screening in adjacent age groups, where the balance between favourable and adverse effects of screening is considered to be worse, could be seen as a negative effect from the public health perspective. Quantifying these mechanisms is important for a complete evaluation of the national screening programme.

In The Netherlands, the general practitioner functions as a gatekeeper to health care. All women who have symptoms of breast cancer or who are concerned about their breasts, have to visit a general practitioner in order to be referred to radiologist or surgeon for mammography. In an existing registration system of 43-45 general practices, a specific item was introduced that related to mammography practice during the build-up period of the screening programme (1988 1995). Using this registry we examined the effect of the start of the screening programme on the number of mammographies requested in general practice.

\section{MATERIALS AND METHODS}

\section{Registration by general practices}

A group of 43-45 general practices (sentinel practices) annually register consultations about specific health problems which are collected and processed by the NIVEL

(Netherlands Institute of Primary Health Care). The population covered by this registration is approximately $1 \%$ of the total population in The Netherlands. These practices are heterogeneous with regard to the degree of urbanisation and geographic area and are considered representative of the total population in The Netherlands [5]. The population covered by the general practice is classified in 5 year age groups and reassessed every 2 years.

The national screening programme was introduced gradually and complete national coverage was reached at the end 1997. Between 1989 and 1997 screening took place in some parts of The Netherlands, but not in others. Since 1988, the number of mammographic examinations requested by general practitioners has been recorded. The present analysis involves all mammographies for which women were referred by their general practitioner and covers the period 1988 to 1995. These mammographies cover the ones made for preventive and for clinical motives (on the basis of complaints or symptoms). These requests were linked to information on the start of the national screening programme (by month and year) in the municipalities of the general practitioners participating in the registry.

\section{Statistical analysis}

All analyses were carried out using the SPSS package. Logistic regression analysis was used to model the chance mammography, depending on whether or not the screening programme had started at that time. Separate logistic regression models were fitted for the age groups studied (30-39, 40-49, 50-69 and 70 + years). In the logistic model, calendar time (in months) was included as a continuous variable. General practice was also included to adjust for different levels of mammography requests.

To describe the effect of the start of the screening programme in the model, the total period covered in each general practice was divided into three intervals. The first interval ended at the start of the screening programme in each practice, the second interval covered the 2 years 
Beemsterboer, P.M.M., Koning, H.J. de, Looman, C.W.N., Borsboom, G.J.J.M., Bartelds, A.I.M., Maas, P.J. van der. Mammography requests in general practice during the introduction of nationwide breast cancer screening, 1988-1995. European Journal of Cancer: 1999, 35(3), 450454

after the start of the programme and the last interval was from 2 years after the start until the end of the observation period. Each interval was modelled, using a separate linear trend with calender time (termed 'Trend'). An instant leap to a new value was allowed at the start of the screening programme, that is at the transition from the first to the second interval (termed 'Start').

The transition from the second to the third interval, however, was continuous (termed 'Rebound'). The difference between the level before the start of the national screening and more than 2 years afterwards was modelled by DIFF. See Figure 1 for the general pattern of mammography. The logistic regression model of the start of the screening was somewhat complex. We also fitted models with a 1 and 3 year interval after the start of screening, but this did not result in a better fit. We tested the underlying trend before and after the start of screening, but this was not statistically signi ficantly different.

\section{RESULTS}

The number of general practices participating in this study ranged from 43 to 45 per year (average duration of participation from 1988 to 1995: 6.4 years). Three practices were in municipalities where experimental screening projects had already been carried out before the start of the national screening programme in 1989. In 1995, in five practices, the national screening programme had not yet begun. The coverage of the national screening programme accorded well with the percentage of general practices where screening had already started, emphasising the representativeness of the sample of the population covered by the general practitioners (data not shown).

\section{[TABLE 1] AND [FIGURE 1]}

During the whole period mammography was requested each year for an average of $2.7 \%$ of the women in the age group $40-49$ years, and for $1.8 \%$ in the age groups $30-39$ years and 50 69 years. For the oldest age group (70 + years) this was $0.5 \%$. The number of mammographies by age and year showed a fluctuating pattern, but overall (and age standardised) a gradual increase occurred from 1988 to 1992, with a gradual decrease from 1993 onwards (Table 1). The age groups 30-39 years and 40-49 years showed less fluctuations than older ages. For the number of mammographies by start of the national screening programme overall (and age standardised), a higher level was observed 0-2 years after the start than before or more than 2 years after the start (Table 1 ).

In Table 2, the average number of mammographies requested by general practitioners is presented, stratified by start of screening. Since screening had already started before 1988 in some municipalities and in others screening did not start in the period studied, Table 2 compares the results from these two groups. In all age groups, the rate of mammography requests was significantly higher if the screening programme had started, compared with practices where screening had not yet started. This could still, however, be only a reflection of differences by general practices or area without reference to the introduction of the screening programme. In the logistic regression model, general practice, calendar time and three parameters for the start of the screening programme (see Materials and Methods) were included. The logistic regression model contained the same variables for all age groups in order to achieve a consistent presentation. The general pattern that emerged from the analyses is shown in Figure 1.

For the youngest age group (30-39 years), almost none of the parameters corresponding to intervals of the start of screening was statistically significant. For all age groups, an increase after the start of screening was observed, but it was most prominent for the age group 50-69 years. The overall time trend in mammography requests was also largest for the ge group 5069 years and for the $70+$ years group (12\% and 14\% increase per year; Table 3). During the 
Beemsterboer, P.M.M., Koning, H.J. de, Looman, C.W.N., Borsboom, G.J.J.M., Bartelds, A.I.M., Maas, P.J. van der. Mammography requests in general practice during the introduction of nationwide breast cancer screening, 1988-1995. European Journal of Cancer: 1999, 35(3), 450454

third interval (more than 2 years after the start of screening), the level of mammography was lower in all age groups, except the youngest. This reduction in mammography examinations was largest and statistically significant for the target population (age 50-69 years) of the national screening programme (odds ratio (OR) 0.56, 95\% confidence interval (CI) 0.460.69 ), but not significant in the adjacent age groups (Table 3). It should be noted that this is over and above the increasing background trend (see Figure 1).

\section{[TABLE 2] [TABLE 3]}

\section{DISCUSSION}

The introduction of the national screening programme has significantly influenced the number of mammography requests by general practitioners, except in the age group 30- 39 years. The number of requests first increased after the start of the programme and then decreased. As expected, the number of mammography requests was significantly lower more than 2 years after the start of the programme in the target age group of the national screening programme (50-69 years) than before. In the adjacent age groups, the number of mammographies was also lower more than 2 years after the start of the screening programme, but the difference was small and not statistically significant.

Increased opportunistic screening under the age of 50 years after the introduction of the screening programme could not be demonstrated in these data. The temporary increase after the start of the national screening programme was less prominent in this age group than for women aged 50-69 years. We would have expected a permanent increase in the number of mammographies that might last more than 2 years after screening had started in the case of opportunistic screening. In some European countries (Sweden, Iceland) screening is carried out for women under the age of 50 years. Screening women under 50 years is still a controversial topic, according to the results of the NIH Consensus Panel. This panel recently concluded that the data currently available do not warrant a universal recommendation for mammography for all women in their forties [6].

Until 1993, women aged 70 years and older were allowed to participate in the screening programme. From 1994 onwards, these women were excluded from the programme. This could have resulted in more mammographies via the general practitioner. Furthermore, these measures have directed attention to screening older women that could itself have resulted in more requests for mammography.

Although it has to be noted that some of the mammographies as requested by the general practitioner were for preventive motives and some for diagnostic motives, we conclude that opportunistic screening in adjacent age groups did not increase after the introduction of the national screening programme for women aged 50-69 years.

During the period of introducing screening for women aged 50-69 years, a continual increase in mammographies was observed in those aged 40 years and over. This could be caused by more breast awareness generated by the programme and other factors, as was suggested in part to be the cause of the decreased mortality from breast cancer in the U.K., pre-dating the effect of screening [7]. In the period before the introduction of the screening programme, the total number of mammographies (radiology departments included) had already shown an increase in The Netherlands, implying that other factors also act on this trend. Furthermore, this increasing background trend was very small in the age group 40-49 years, who would be expected to be most sensitive to breast awareness resulting from the screening programme.

The temporary rise (followed by a decline) in the number of mammography requests $0-2$ years after the local introduction of the national screening programme is somewhat surprising for the age group 50-69 years. When asked about this result, the participating general practitioners said they were confident that only mammographies outside the national screening programme had been registered, even in this age group. These were, 
Beemsterboer, P.M.M., Koning, H.J. de, Looman, C.W.N., Borsboom, G.J.J.M., Bartelds, A.I.M., Maas, P.J. van der. Mammography requests in general practice during the introduction of nationwide breast cancer screening, 1988-1995. European Journal of Cancer: 1999, 35(3), 450454

however, self-reported data (data not shown). The increase could be an artefact caused by extra alertness of the general practitioners to register mammographies after the start of screening. This would imply that the real number $\mathrm{f}$ mammography requests before the start of screening and possibly also more than 2 years after screening was introduced was underestimated. Another explanation of these results might be that women who had not yet received an invitation, were encouraged by publicity surrounding the introduction of screening in their municipality to have a ammography via their general practitioner. Furthermore, women who already have breast problems or symptoms might not wait for the screening invitation but consult their general practitioner immediately. It is also possible that the general practitioners refer, for a clinical mammography, women who did not attend screening. A small loss in attendance at the population level could have a relatively high impact on mammography numbers in general practice. Literature regarding these issues is scarce. Garstin and colleagues observed a $42 \%$ increase in mammographies after the start of the national screening programme in the U.K., which was mainly caused by referral by menopausal clinics and general practitioners [8]. In that study, concern was raised that double screening might take place or a false sense of security would occur.

The decrease in mammography requests by the general practitioner in the target population of the Dutch national screening programme can be interpreted as an effect of the introduction of screening. Part of this reduction may be due to false reassurance after a negative screen result. Still, a considerable number of breast cancer cases are diagnosed in the interval between two screening examinations $[9,10]$. False reassurance might result in less cancers detected in the interval and, thus, an undesirable delay of diagnosis and treatment. Additional (qualitative) research is needed to unravel further the occurrence of false reassurance and to interpret the sudden rise (and decline) as observed in this study.

The population covered by the general practices of the NIVEL is representative of the total Dutch population with respect to degree of urbanisation and geographic spread [5]. The general practitioners may not be representative of all general practitioners. Participating in the registration is on a voluntary basis and it could be argued that this implies some selection. These general practitioners could, for example, be more restrictive in referring patients for mammography. Such selection would influence the overall level of mammography referrals, but is unlikely to lead to other conclusions. Some general practices contributed more to the time trend before the start of the screening programme whilst others contributed more to the trend after the start. By including the general practice as a confounding variable, we adjusted for this.

Only $1.8 \%$ of all women have a mammography via their general practitioner each year, whilst $80 \%$ of all women aged 50-69 years attend the biennial screening in The Netherlands. The relative changes, as represented by the ORs, observed in this study were quite large, but have to be interpreted within this perspective.

In this study, the start of a national screening programme had a large temporary effect on the level of mammography requests by general practitioners. We have no information on whether this is caused by a change in requests by the women themselves, a change in policy of the general practitioner, or both. A decrease of mammography requests in the target population of the screening programme (age 50-69 years) was observed after some time. It may reflect the increased uptake of breast cancers and true negative results by the national screening programme and certainly supports the hypothesis that a screening programme reduces the number of clinical mammographies. Our study shows that at the same time it seems not to result in a permanent increase in opportunistic screening in women from adjacent age groups. 
Beemsterboer, P.M.M., Koning, H.J. de, Looman, C.W.N., Borsboom, G.J.J.M., Bartelds, A.I.M., Maas, P.J. van der. Mammography requests in general practice during the introduction of nationwide breast cancer screening, 1988-1995. European Journal of Cancer: 1999, 35(3), 450454

\section{REFERENCES}

1. de Koning $\mathrm{HJ}$, Fracheboud J, Boer R, et al. Nationwide breast cancer screening in The Netherlands: support for breast-cancer mortality reduction. National Evaluation Team for Breast Cancer Screening (NETB). Int J Cancer 1995, 60(6), 777-780.

2. Fracheboud J, de Koning $\mathrm{HJ}$, Beemsterboer PMM, et al. Nationwide breast cancer screening in the Netherlands: results of initial and subsequent screening 1990-1995. Int J Cancer 1998, 75, 694-698.

3. de Koning $\mathrm{HJ}$, van Ineveld BM, van Oortmarssen GJ, et al. Breast cancer screening and cost-effectiveness; policy alternatives, quality of life considerations and the possible impact of uncertain factors. Int J Cancer 1991, 49(4), 531-537.

4. de Koning $\mathrm{HJ}$, van Oortmarssen GJ, van Ineveld BM, van der Maas PJ. Breast cancer screening: its impact on clinical medicine. Br J Cancer 1990, 61(2), 292-297.

5. Bartelds AIM. Continue morbiditeits registratie Nederland, 1995. Utrecht, NIVEL (Netherlands Institute of Primary Health Care), 1996.

6. National Institutes of Health Consensus Development Panel. National Institutes of Health Consensus Development Conference statement: breast cancer screening for women ages 40-49, January 21-23, 1997. J Natl Cancer Inst 1997, 89(14), 1015-1025.

7. Stockton D, Davies T, Day N, McCann J. Retrospective study of reasons for improved survival in patients with breast cancer in beast Anglia: earlier diagnosis or better treatment. Br Med J 1997, 314(7079), 472-475.

8. Garstin IW, Kaufman Z, Michell MJ, Rodway A, Ebbs SR, Baum M. Side-effects of screening. Eur J Cancer 1993, 29A(15), 2150-2152.

9. Day N, McCann J, Camilleri-Ferrante C, et al. Monitoring interval cancers in breast screening programmes: the east Anglian experience. Quality Assurance Management Group of the East Anglian Breast Screening Programme. J Med Screen 1995, 2(4), 180185.

10. Tabar L, Fagerberg G, Duffy SW, Day NE, Gad A, Grontoft O. Update of the Swedish two-county program of mammographic screening for breast cancer. Radiol Clin North Am 1992, 30(1), 187-210.

\section{TABLES AND FigURES}


Table 1. Number of participating general practices and number of mammographies by age and start of screening per year (per 10000$)$

\begin{tabular}{lrrrrrrrrr}
\hline & 1988 & 1989 & 1990 & 1991 & 1992 & 1993 & 1994 & 1995 & $1988-1995$ \\
\hline $\begin{array}{l}\text { Participating general practices } \\
\text { \% of general practices where screening started }\end{array}$ & 45 & 45 & 44 & 43 & 43 & 45 & 45 & 45 & \\
Age & - & 4 & 16 & 9 & 21 & 24 & 22 & 11 & \\
$\quad$ 30-39 years & 162 & 164 & 147 & 166 & 186 & 192 & 220 & 199 & 180 \\
$\quad$ 40-49 years & 200 & 233 & 231 & 295 & 277 & 275 & 323 & 300 & 269 \\
$\quad 50-69$ years & 103 & 120 & 158 & 197 & 151 & 323 & 218 & 192 & 184 \\
$\quad$ 70 + years & 24 & 25 & 39 & 55 & 41 & 87 & 65 & 59 & 50 \\
Start of screening & & & & & & & & & \\
$\quad$ Before start (age standardised) & 129 & 139 & 150 & 170 & 177 & 156 & 190 & 169 & 157 \\
$\quad$ 0-2 years after start (age standardised) & - & 200 & 212 & 276 & 172 & 376 & 259 & 194 & 267 \\
$\quad$ 2 years after start (age standardised) & 105 & 164 & 110 & 203 & 138 & 148 & 198 & 207 & 175 \\
Total (age standardised) & 127 & 141 & 151 & 186 & 170 & 235 & 216 & 195 & 179 \\
Absolute numbers & 471 & 514 & 542 & 646 & 572 & 708 & 718 & 663 & 4834 \\
\hline
\end{tabular}

$\star$ In three practices screening had already started as the result of an experimental screening project in 1974-1975. 
Beemsterboer, P.M.M., Koning, H.J. de, Looman, C.W.N., Borsboom, G.J.J.M., Bartelds, A.I.M., Maas, P.J. van der. Mammography requests in general practice during the introduction of nationwide breast cancer screening, 1988-1995. European Journal of Cancer: 1999, 35(3), 450454

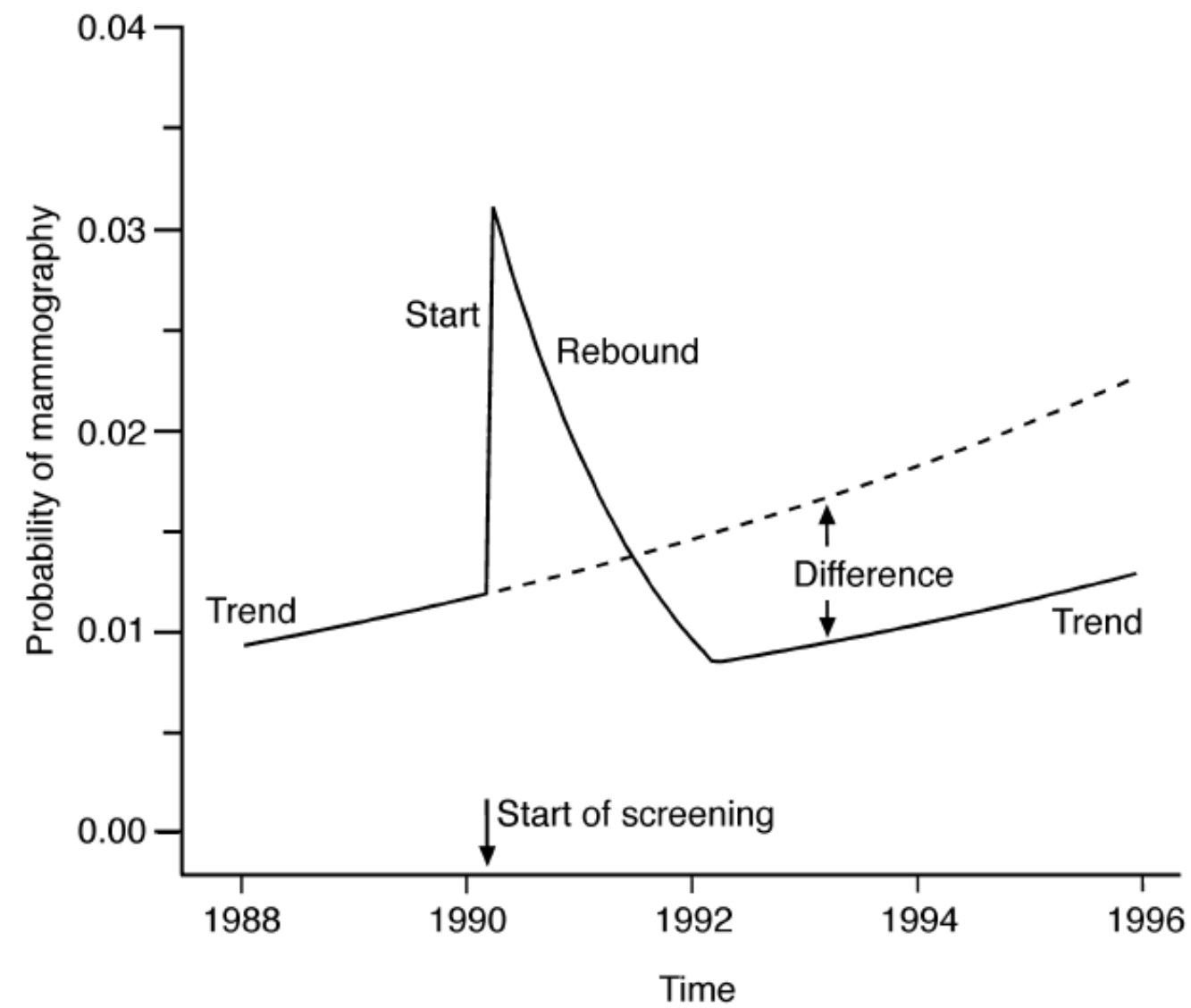

Figure 1. General pattern of mammography requests, age group 50-69 years. 
Table 2. Number of mammographies per 10000 women by age and start of screening, 1988-1995

\begin{tabular}{lcccc}
\hline & & \multicolumn{3}{c}{ Age group } \\
\cline { 2 - 5 } Screening & $\begin{array}{c}30-39 \text { years } \\
\text { Rate }(95 \% \mathrm{CI})\end{array}$ & $\begin{array}{c}40-49 \text { years } \\
\text { Rate }(95 \% \mathrm{CI})\end{array}$ & $\begin{array}{c}50-69 \text { years } \\
\text { Rate }(95 \% \mathrm{CI})\end{array}$ & $\begin{array}{c}70+\text { years } \\
\text { Rate }(95 \% \mathrm{CI})\end{array}$ \\
\hline Not (yet) started & $166(156-176)$ & $237(224-250)$ & $151(142-160)$ & $36(30-42)$ \\
Started & $208(192-223)$ & $329(309-350)$ & $238(224-253)$ & $70(60-80)$ \\
\hline
\end{tabular}

CI, confidence interval.

Table 3. Relationship between the start of screening, age and mammography requests with adjustment for calendar time and general practice (separate age models, see also Figure 1)

\begin{tabular}{lcccc}
\hline & \multicolumn{4}{c}{ Age group } \\
\cline { 2 - 5 } & $\begin{array}{c}\text { 30-39 years } \\
\text { OR }(95 \% \mathrm{CI})\end{array}$ & $\begin{array}{c}40-49 \text { years } \\
\text { OR }(95 \% \mathrm{CI})\end{array}$ & $\begin{array}{c}50-69 \text { years } \\
\text { OR }(95 \% \mathrm{CI})\end{array}$ & \begin{tabular}{c}
$70+$ OR $(95 \% \mathrm{CI})$ \\
\hline Underlying TREND (per year)
\end{tabular} \\
\hline START & $0.99(0.96-1.02)$ & $1.03(1.00-1.06)$ & $1.12(1.09-1.16)$ & $1.14(1.05-1.24)$ \\
REBOUND (0-2 years; trend per year) & $1.12(0.90-1.38)$ & $1.29(1.08-1.54)$ & $2.79(2.40-3.24)$ & $1.74(1.13-2.67)$ \\
DIFF (level before START-level after REBOUND) & $1.05(0.92-1.20)$ & $0.88(0.79-0.98)$ & $0.50(0.46-0.55)$ & $0.84(0.66-1.07)$ \\
\hline
\end{tabular}

OR, odds ratio; CI, confidence interval. 